PressAcademia Procedia

YEAR 2018 VOLUME 7

4th Global Business Research Congress, May 24-25, 2018, Istanbul, Turkey.

\title{
DO BRAND LOVE LEVELS FOR SMART PHONE BRANDS DIFFER? A RESEARCH ON UNIVERSITY STUDENTS
}

DOI: 10.17261/Pressacademia.2018.895

PAP- V.7-2018(48)-p.268-271

Volkan Ozbek ${ }^{1}$, Oykem Dogan ${ }^{2}$

${ }^{1}$ Balikesir University, Burhaniye UBYO, Uluslararası Ticaret Bölümü, Balikesir, Turkey. vozbek@balikesir.edu.tr, ORCID: 0000-0002-2140-2709

${ }^{2}$ Balikesir University, SBE, Uluslararası Ticaret ve Pazarlama ABD, Balikesir, Turkey. oykemdogan@gmail.com, ORCID: 0000-0002-3381-5527

To cite this document

Ozbek, V., Dogan, O. (2018). Do brand love levels for smart phone brands differ? a research on university students. PressAcademia Procedia (PAP), V.7, p.268-271.

Permemant link to this document: $\mathrm{http}: / /$ doi.org/10.17261/Pressacademia.2018.895

Copyright: Published by PressAcademia and limited licenced re-use rights only.

\section{ABSTRACT}

Purpose- The aim of this study is to determine university students' brand love levels towards smart phone brands and reveal whether brand love levels differ according to brands such as Apple, Samsung, and other brands.

Methodology- The research was implemented on 707 university students determined with convenience sampling and survey method was used. In this context, variance analysis was implemented to reveal if brand love levels of university students using different smart phone brands differ or not. Data was analyzed through descriptive statistics, one-way-ANOVA and independent sample t-test.

Findings- In the scope of this study, it is determined that brand love levels toward smart phone brands differ and the highest brand love is toward Apple smart phones.

Conclusion- Based on these findings, it is possible to say that brand love levels on smart phones differ. Firms wanting to have competitive advantage should read well this result. This result could be interpreted as firms in this sector should concentrate on marketing strategies that increase brand love.

Keywords: Brand love, smart phone, Apple, Samsung.

JEL Codes: M30, M31

\section{AKILLI TELEFON MARKALARINA YÖNELIK MARKA AŞKI DÜZEYLERI FARKLILIK GÖSTERIR MI? ÜNIVERSiTE ÖĞRENCILERI ÜZERINDE BIR ARAŞTIRMA}

ÖZET

Amaç- Bu araştırmanın amacı, üniversite öğrencilerinin akıllı telefon markalarına yönelik marka aşkı düzeylerini belirlemek ve Apple, Samsung ve diğer markaların marka aşkı düzeylerinin farklılaşıp farklılaşmadığını ortaya koymaktır.

Yöntem- Araştırma, kolayda örnekleme yöntemi ile ulaşılan 707 üniversite öğrencisi üzerinde anket yöntemiyle yürütülmüştür. Bu bağlamda, farklı markalara sahip öğrencilerin marka aşkı düzeylerinin farklılaşıp farklılaşmadığını ortaya koymak amacıyla Varyans Analizi yapılmıştır. Verilerin analizi, betimleyici istatistikler, tek yönlü varyans analizi ve bağımsız örneklem t-testi üzerinden yürütülmüştür.

Bulgular- Araştırma kapsamında, akılı telefon markalarına yönelik marka aşkı düzeylerinin farklılık gösterdiği; en yüksek marka aşkı düzeyinin Apple marka akıllı telefonlarda gerçekleştiği bulunmuştur.

Sonuç- Araştırma bulgularından yola çıkarak, akıllı telefon markalarında marka aşkı düzeylerinin farklılık gösterdiği söylenebilir. Rekabette öne geçmek isteyen firmalar bu sonucu iyi değerlendirmelidir. Bu sonuç, sektörde faaliyette bulunan firmaların marka aşkını artırmaya yönelik pazarlama taktiklerine ağırlık vermeleri gerektiği şeklinde yorumlanabilir.

Anahtar Kelimeler: Marka aşkı, akıllı telefon, Apple, Samsung.

JEL Kodları: M30, M31 


\section{GiRiş}

Günümüz tüketim dünyasında, markaların taşıdıkları fonksiyonel faydaların yanında sembolik anlamları da tüketicilerin satın alma kararlarında rol oynamaktadır. Bu durum karşısında firmaların rekabetçi güç elde edebilmeleri, markalarını her yönden besleyerek aşk markaları haline getirmeleri ile mümkündür. Pazarlama literatüründe geçmişten beri markaları sevme duyguları üzerine çalışılmış olmasına rağmen, "marka aşkı" konusuna gösterilen ilginin ancak son yıllarda arttığı görülmüştür (Aydın, 2017). Geleneksel pazarlama yaklaşımına göre, tüketiciler sadece ürünlerin işlevsel özellikleri ve faydalarına önem veren rasyonel karar verme mekanizmalarıdır. Ancak, gerçekte tüketiciler karar verirken sadece rasyonel değil, aynı zamanda duygusal davranmaktadırlar (Aşkın ve İpek, 2016). Günümüz tüketim dünyasında ise her şey markalaşmakta ve tüketicilerin markalarına sevgiden öte bir duyguyla "aşk"la bağlandıkları görülmektedir. Ayrıca yaşamlarının her alanına teknolojiyi yerleştiren tüketiciler duygularını yeniliklerle ifade etmeye başlamışlardır. Hatta bazı tüketiciler markaları ile ilgili duygularını "tekno-aşk" ve "tekno-romantik" gibi ifadelerle yansıtmaktadırlar (Önen, 2018).

Günümüzde hayatın bir parçası haline gelen, konuşma ve mesajlaşma dışında birçok işlemin yapılabildiği akıllı cep telefonları çok büyük bir pazar oluşturmaktadır. 2017 yılının 2. çeyreğinde Samsung dünya genelinde 79,5 milyon adet akılı telefon satışı ile pazarın açık ara lideri olurken, Apple 41 milyon adet ile ikinci sırada yer almıştır. Bu nedenle bu çalışmada Samsung ve Apple markalarına yönelik marka aşkı düzeyleri ayrı ayrı değerlendirilirken, diğer tüm markalar tek kategoride incelenmiştir.

\section{LITERATÜR ARAŞTIRMASI}

Marka aşkı kavramı, geçmişi oldukça yeni olmakla birlikte, giderek ilgi çeken bir kavrama dönüşmektedir. Aaker (1997)'e göre insanlar sadece kişilerarası ilişkilerde (seni seviyorum) değil, aynı zamanda tüketim ürünleri bağlamlarında (arabamı seviyorum, cep telefonumu seviyorum) sevme gibi süreçleri yaşamaktadır. Whang ve arkadaşları (2004) diğer araştırmacılar gibi marka aşkı ve kişilerarası aşkın benzerliklerinden değil, önemli bir farkından bahsetmişlerdir. Onlara göre marka aşkı tek yönlü (yani sadece müşterinin markaya karşı sevgi hissetmesi), kişilerarası aşk ise çift yönlüdür. Langner ve arkadaşlarının (2015) yaptığı bir araştırmaya göre kişilerarası (romantik) aşk ve marka aşkı farklı duygulardan oluşturmaktadır. Çalışmalarında, marka ilişkilerinin çoğunlukla akılcı yararlardan kaynaklandığı, kişilerarası sevginin ise genellikle duygusal olduğu vurgulanmaktadır. Yani, marka sevgisinin duygusal deneyiminin kalitesi, kişilerarası bir aşk ilişkisinin duygusal kalitesinden farklıdır. Marka aşkının araştırıldığı çalışmalar genelde kişilerarası aşkın tanımı ile başlamış ve bunu tüketicilerin markaya duyduğu aşkın açıklanması takip etmiştir.

Markalar günümüzün giderek artan rekabet ortamında rakiplerine üstünlük sağlamayı, kalıcı olmayı hedeflemektedirler. Pazara sürekli yeni markaların girmesiyle beraber rekabet iyice artmakta ve markaların işleri giderek zorlaşmaktadır. Bu yüzden markalar müşterilerinin gözünde ve kalbinde, diğer markalardan daha farklı ve daha üstün bir yerde olmak istemektedirler. Markalar artık, sadakat ve memnuniyetten biraz daha ileride olan kendilerine âşık müşteriler yaratma peşindedirler. Çünkü markalarına âşık müşteriler, ondan memnun olmakta ve sadık müşterilere göre markalarından daha zor vazgeçmektedirler. Böylece markalarına âşık durumda olan müşteriler ile markalar arasındaki ilişki diğer durumdaki ilişkilere göre daha uzun sürmektedir. Günümüzde şirketler, marka ile ilgili sevgi duygusunun, müşterilerle iyi bir ilişki kurulmasında hayati bir faktör olduğunu fark etmişlerdir (Roberts, 2006). Müşterilerine kendilerini sevdiren markalar, sürdürülebilir avantaj elde etme ve rakiplerini yenme konusunda daha başarılıdır. Rossiter (2012)'in yapmış olduğu bir araştırmada marka aşkı ile marka beğenisi karşılaştırılmıştır. Bu çalışmaya göre, bir markayı kullanmaya başlayan müşterilerin yaklaşık dörtte biri markayı sevmeye başlamaktadır. Markayı sevmek ise markayı beğenmeye göre davranışsal olarak farklılık göstermektedir. Markayı sevenlerin markayı beğenenlere kıyasla, tekrar satın alma düzeyi, markayı kullanma oranı ve markayı başkalarına tavsiye etme düzeyinin yaklaşık iki katına çıktığı görülmüştür. Sadece bu bulgular bile firmalar açısından marka aşkının ne kadar önemli olduğunu göstermek için yeterlidir.

Sternberg (1986) bir çalışmasında kişilerarası sevginin, birbiriyle ilişkili olan üç boyuttan oluştuğunu belirtmektedir. Bu boyutlar samimiyet, tutku ve karar olarak açıklanmıştır. Sternberg ayrıca sevginin olabilmesi için üç boyutun da gerçekleşmesinin şart olmadığını belirtmiştir. Ancak üç boyutun hepsinin gerçekleşmesiyle "tam sevgi" oluşacaktır. Sternberg'in kişilerarası sevgi için oluşturduğu bu boyutlar marka aşkı için de kullanılmıştır. Shimp ve Madden (1988), Sternberg'in (1986) üçlü kişilerarası kavramsallaştırmasını temel alarak üç boyutlu tüketici marka ilişkisini beğenme, özlem ve karar/taahhüt şeklinde ortaya koymuştur. Beğenme samimiyete, özlem ise tutku duygularına denk gelmektedir. Taahhüt ise müşterinin aynı markayı ard arda tercih etmesidir. Akıllı telefon üzerinden bir örnek vermek gerekirse, kullandığı cep telefonu markasından memnun olan kullanıcı o telefon markasını uzun yıllar kullanmak isteyebilir ve telefonunu yenileyeceği zaman yine o markanın yeni çıkan modellerini tercih edebilir.

\section{YÖNTEM}

Bu araştırmanın temel amacı, üniversite öğrencilerinin akıllı telefon markalarına yönelik marka aşkı düzeylerini belirlemek ve Apple, Samsung ve diğer markaların marka aşkı düzeylerinin farklılaşıp farklılaşmadığını ortaya koymaktır. Bu amacın yanı sıra aynı markanın kullanıldığı yıla ve aynı markadan kullanılan telefon sayısına göre marka aşkının farklılaşıp farklılaşmadığı da araştırma kapsamında incelenmiştir. Dolayısıyla araştırmada üç hipotez bulunmaktadır. Araştırmanın ana kütlesi Balıkesir Üniversitesi'ne bağlı iki yüksekokulun öğrencilerinden oluşmaktadır. Saha çalışması Şubat-Mart 2018 tarihleri arasında anket yöntemiyle gerçekleştirilmiştir. Dağıtılan 800 anket formundan eksik ve yanlış doldurulanlar analiz kapsamından çıkarılmış ve 707 anket formu ile analizler gerçekleştirilmiştir.

Araştırmanın amacına yönelik olarak hazırlanmış olan anket formu A ve B olmak üzere iki bölümden oluşmaktadır. İlk bölümde cevaplayıcıların demografik özelliklerini ölçmeye yönelik sorular yer almaktadır. İkinci bölümde marka aşkı değişkenini ölçmeye yönelik toplam 5 ifade yer almaktadır. Araştırmada kullanılan marka aşkı ölçeğinin (Carroll ve Ahuvia, 2006) 5 sorusu Aydın’ın (2016) çalışmasından adapte edilerek kullanılmıştır. 


\section{ARAŞTIRMANIN BULGULARI}

\subsection{Frekans Dağılımları}

Araştırmaya katılan cevaplayıcıların cinsiyetleri ve kullandıkları cep telefonu markaları Tablo 1 ve Tablo 2'de görülmektedir.

Tablo 1: Cevaplayıcıların Cinsiyetlerine Göre Dağılımı

\begin{tabular}{|l|l|l|l|}
\hline Cinsiyet & Kadın & Erkek & Toplam \\
\hline Frekans & 374 & 333 & 707 \\
\hline Yüzde & 52,9 & 47,1 & 100 \\
\hline
\end{tabular}

Tablo 2: Cevaplayıcıların Kullandığı Cep Telefonu Markasına Göre Dağılımı

\begin{tabular}{|l|l|l|l|l|}
\hline Marka & Apple & Samsung & Diğer & Toplam \\
\hline Frekans & 280 & 262 & 165 & 707 \\
\hline Yüzde & 39,6 & 37,1 & 23,3 & 100 \\
\hline
\end{tabular}

\subsection{Güvenilirlik Analizi Bulguları}

Araştırma sorularının güvenilirliğini ölçmek amacıyla Likert ölçeği ile ölçüm gerçekleştirilen çalışmalarda yaygın bir biçimde kullanılan Cronbach'ın Alfa Katsayısı kullanılmıştır. Yapılan analiz sonucunda, 5 maddeden oluşan marka aşkı ölçeğinin Alfa Katsayısı 0,881 olarak hesaplanmıştır. Bu değer, kritik değer olarak kabul edilen 0,70'in oldukça üzerindedir (Nakip, 2006, s.145).

\subsection{Hipotezlerin Testi}

Araştırmanın amacına yönelik olarak hazırlanan birinci hipotez "Akıllı telefon markalarına yönelik marka aşkı düzeyleri farklılık göstermektedir" şeklinde kurgulanmıştır. Bu hipotezi test etmek amacıyla üç farklı kategorinin (Apple, Samsung ve Diğer) ortalamalarının birbirinden farklı olup olmadığının ortaya konmasına olanak tanıyan Tek Yönlü Varyans Analizi (ANOVA) kullanılmıştır. Analiz sonuçları Tablo 3'te görülmektedir.

Tablo 3: Akıllı Telofon Markalarının Marka Aşkı Ortalamaları

\begin{tabular}{|l|l|l|l|l|}
\hline Marka & Frekans & Ortalama & F & P \\
\cline { 1 - 3 } Apple & 280 & 3,83 & \multirow{3}{*}{77,674} & \multirow{2}{*}{0,001} \\
\cline { 1 - 3 } Samsung & 262 & 3,39 & & \\
\hline Diğer & 165 & 2,89 & \\
\hline
\end{tabular}

Tüm akıllı telefon markalarına yönelik marka aşkı düzeyinin 3,45 olarak bulunduğu analizlerde, markaların ayrı ayrı ortalamaları incelendiğinde, Apple'ın 3,83, Samsung'un 3,39 ve diğer markaların 2,89 olarak hesaplandığı görülmüştür (Tablo 3). Bu ortalamaların birbirinde farklı olup olmadığını gösteren ANOVA testi sonucunda, Apple, Samsung ve diğer markaların marka aşkı düzeylerinin birbirinden farklı olduğu ortaya konmuştur $(p<0,001)$. Scheffe tekniğiyle yapılan Post Hoc testi sonucunda ise her bir kategorinin marka aşkı düzeyinin birbirinden farklı olduğu tespit edilmiştir. Bu nedenle $\mathrm{H} 1$ hipotezi desteklenmiştir.

Araştırmanın ikinci hipotezi "Akılı telefon markasının kullanım süresine göre marka aşkı düzeyi değişmektedir" şeklinde kurgulanmıştır. Tablo 4'te görüldüğü gibi, "3 yıl ve üstü" ile "1 veya 2 yıl” olmak üzere iki cevap kategorisinin bulunduğu hipotezin bağımsız örneklem t testi ile analiz edilmesi sonucunda 3 yıl ve üzerinde bir süredir aynı akıllı telefon markasını kullananların $(3,55)$ marka aşkı düzeylerinin 1 veya 2 yıldır aynı markayı kullananlardan $(3,33)$ daha yüksek olduğu ortaya konmuştur $(p<0,001)$. Bu nedenle H2 hipotezi desteklenmiştir.

\section{Tablo 4: Kullanım Süresine Göre Marka Aşkı}

\begin{tabular}{|l|l|l|l|l|}
\hline YIL & FREKANS & ORTALAMA & t & P \\
\hline $\mathbf{3}$ yıl ve üstü & 385 & 3,55 & \multirow{2}{*}{3,332} & \multirow{2}{*}{0,001} \\
\cline { 1 - 2 } veya 2 yıl & 322 & 3,33 & \\
\hline
\end{tabular}

Araştırmanın üçüncü hipotezi "Akıllı telefon markasının kullanım sayısına göre marka aşkı düzeyi değişmektedir" şeklinde kurgulanmıştır. Tablo 5'te görüldüğü gibi, "1 veya 2" ve "3 ve üstü" olmak üzere iki cevap kategorisinin bulunduğu hipotezin bağımsız örneklem t testi ile analiz edilmesi sonucunda aynı markanın 3 ve üzerinde bir sayıda telefonunu kullananların $(3,66)$ marka aşkı düzeylerinin 1 veya 2 kez kullananlardan $(3,38)$ daha yüksek olduğu ortaya konmuştur $(p<0,001)$. Bu doğrultuda H3 hipotezi desteklenmiştir.

Tablo 5: Kullanım Sayısına Göre Marka Aşkı

\begin{tabular}{|l|l|l|l|l|}
\hline Telefon Sayısı & FREKANS & ORTALAMA & t & P \\
\hline 3 ve üstü & 186 & 3,66 & \multirow{2}{*}{4,093} & \multirow{2}{*}{0,001} \\
\hline 1 veya 2 & 521 & 3,38 & 4,00 \\
\hline
\end{tabular}




\section{SONUÇ VE ÖNERILER}

Rekabetin giderek arttığı, pazarda tutunmanın iyice zorlaştığı günümüz koşullarında firmalar ayakta kalmanın, zirveye doğru ilerlemenin yollarını aramaktadır. Daha önceleri memnuniyet ve sadakat kavramı firmalar için yeterli olsa da artık müşteriler için alternatiflerin çoğalması ile birlikte bunlar yeterli gelmemektedir. Bu yüzden firmalar müşterilerle olan bağı bir seviye daha ileri götürüp müşterilerini kendi markalarına aşık etmeye ve başka markaya gitmemelerini sağlamaya çalışmaktadır.

Araştırma sonucunda kullanılan akıllı telefon markalarının marka aşkı düzeylerinin farklılaştığı tespit edilmiştir. Buna göre, cevaplayıcıların marka aşkı düzeyleri sırasıyla Apple, Samsung ve diğer markalar şeklinde sıralanmıştır. Markalara göre aşk düzeylerinin farklı olmasında markanın müşteriye sunmuş olduğu yenilik, güven, imaj, memnuniyet gibi kavramların etkili olduğu düşünülmektedir.

Araştırmanın ikinci hipotezi ile katılımcıların aynı markanın telefonunu kullanma yılının marka aşkı düzeyini değiştirip değiştirmediği incelenmiştir. Buna göre 3 yıl ve daha uzun süredir aynı markayı kullananların marka aşkı düzeylerinin daha yüksek olduğu görülmüştür. Bu bulgu, marka sadakati ile marka aşkı arasındaki ilişkiyi göstermesi bakımından önemlidir. Araştırmanın üçüncü hipotezinde aynı markadan kullanılan akıllı telefon sayısının marka aşkı düzeyini değiştirip değiştirmediği incelenmiştir. Araştırma bulguları aynı markanın 3 veya daha fazla telefonunu kullananların 1 veya 2 telefonunu kullananlara göre daha yüksek marka aşkı düzeyine sahip olduğunu göstermektedir. Bu bulgu, aynı markadan kullanılan telefon sayısı arttıkça markaya olan aşk düzeyinin de artacağını göstermektedir.

Araştırma sonuçları, marka aşkının akıllı telefon markaları açısından ne kadar önemli olduğunu ortaya koymaktadır. Bu nedenle firmalara markalarına aşık bir tüketici kitlesi oluşturmaları önerisinde bulunulabilir. Bu bağlamda firmalar pazarlama çalışmalarında duygusal unsurlara ve marka aşkını artıracak çabalara daha fazla ağılık vermelidir. Marka aşkı konusunda araştırma yapmak isteyen akademisyenlere ise, çeşitli öncüllerin marka aşkı üzerindeki etkilerine ve marka aşkının etkilediği sonuç değişkenlere odaklanmaları önerisinde bulunulabilir. Bunun yanında, akıllı telefon sektöründe marka aşkı farklı markalar arasında karşılaştırmalar yapılarak da incelenebilir. Ayrıca, başka sektörlerde ve farklı markalar üzerinde tüketicilerin marka aşkı düzeyleri incelenebilir.

\section{KAYNAKLAR}

Aaker, J. L. (1997). Dimensions of brand personality. Journal of Marketing Research, 34(3): 347-356.

Aşkın, N., Ipek, I. (2016). Marka aşkının marka deneyimi ile marka sadakati arasındaki ilişkiye aracılık etkisi. Ege Academic Review, 16(1).

Aydın, H. (2017). Marka güveni, farkındalığı ve benlik imaj uyumunun marka bağlılığına etkisinde marka aşkının aracılık rolü. Ege Academic Review, 17(2).

Langner, T., Schmidt, J., Fischer, A. (2015). Is it really love? A comparative investigation of the emotional nature of brand and interpersonal love. Psychology \& Marketing, Volume 32, Issue 6 June 2015 Pages 624-634.

Nakip, M. (2006). Pazarlama araştırmaları teknikler ve SPSS destekli uygulamalar. Ankara: Seçkin Yayıncılık.

Önen, V. (2018). Marka değerinin marka aşkına etkisinin incelenmesi: Starbucks cafe örneği. Sosyal Araştırmalar Dergisi, 5(1), p.49-63.

Roberts, K. (2006). Love marks: the future beyond brands. New York: Power House Books.

Rossiter, J. R. (2012). A new C-OAR-SE-based content-valid and predictively valid measure that distinguishes brand love from brand liking. Marketing Letters. September 2012, Volume 23, Issue 3, pp 905-916.

Shimp, T. A., Madden, T. J. (1988). Consumer-object relations: a conceptual framework based analogously on Sternberg"s triangular theory of love. Advances in Consumer Research, 15(1), 163-168.

Sternberg, R. J. (1986). A triangular theory of love. Psychological Review, Vol.93, No.2, pp.119-135.

Whang, Y. O., Allen, J., Sahoury, N., Zhang, H. (2004). Falling in love with a product: the structure of a romantic consumer-product relationship. Advances in Consumer Research, 31, 320-327. 